Journal of Teacher Education for Sustainability, vol. 15, no. 1, pp. 57-72, 2013

\title{
REFLECTIONS OF DESIGN-ORIENTED PEDAGOGY FOR SUSTAINABLE LEARNING: AN INTERNATIONAL PERSPECTIVE
}

\author{
Henriikka Vartiainen and Jorma Enkenberg \\ University of Eastern Finland, Finland
}

\begin{abstract}
This paper focuses on the expansion of design-oriented pedagogy that encourages approaching global phenomena such as sustainable development from the perspective of local environments, cultures and associated ways of doing things. It aims to determine how project members and teachers from eight different European countries $(n=221)$ who had participated in the project "Case Forest - pedagogy towards sustainable development" experienced the pedagogical model and evaluated its usability from the perspectives of their own educational cultures. The main sources of both theory and data-driven qualitative content analysis are the reports obtained from each country and transcripts of the oral presentations and collaborative discussions. The results indicate that the teachers find current school practices, belief systems and traditional teaching models problematic and see the model as one way to change their schools' practices towards sustainable learning.
\end{abstract}

Key words: pedagogical model, design-oriented pedagogy, design-based research

\section{Introduction}

Sustainable development is related to the values, activities and practices of individuals, communities and organisations, required for a sustainable society and future. The key challenge of our time should be addressed in multiple ways from different vantage points in locally grounded but globally connected ways (United Nations Educational, Scientific and Cultural Organisation [UNESCO], 2009). As stated in UNESCO documents (1998, 2005, 2009), education is essential for moving towards a more sustainable future as the world's hopes for the future rest with today's children and young people and their readiness to take up the complex challenges of today and the future.

Education for sustainable development calls for new kinds of learning that are not so much of a transmissive nature but rather of a transformative and continuous engagement in sustainability in formal, non-formal and informal settings. The complex and multi-disciplinary nature of sustainable development requires intensive collaboration between disciplines, schools and the wider community, along with the capacity to connect and reconcile multiple ways of looking at the world (UNESCO, 2005, 2009). 
To meet these challenges and to offer teachers tools to facilitate teaching and learning for sustainable development, a consortium consisting of 12 partners from eight different countries was formed: Sweden, Finland, Estonia, Latvia, Lithuania, the Czech Republic, Slovakia and Bulgaria. This study focuses on the project entitled "Case Forest - pedagogy towards sustainable development”, which was based on design-oriented pedagogy, developed by a research group led by Professor Jorma Enkenberg. The present study aimed to determine how teachers that represent different educational cultures and backgrounds experience the pedagogy and evaluate its usability.

\section{Towards sustainable learning}

In a recent UNESCO publication, Kozma (2011) argued that while people in the 'outside world' work collaboratively and use a variety of digital tools and resources to solve complex problems and create new ideas and products, students in schools have remained in structured classrooms where teachers cover the standard content by lecturing a large class of students. Students work individually and reproduce this knowledge that is then assessed, and their use of information and communication technology (ICT) is limited. Furthermore, an international survey of teachers from 23 countries (Law, Pelgrum, \& Plomp, 2008) supported this argument as the three most common classroom pedagogical practices were: having students fill out worksheets, working at the same pace and sequence and answering tests. ICT was rarely used. Given the role of education and schools in society, the question that arises is: Is this type of educational system capable of educating individuals to meet the challenges they will face in the emerging society?

As the pace of change in the twenty-first century increases, many researchers have shifted their focus from education to life-long learning. Learning is a lifelong process that occurs in various situations (life-wide) and in cultural practices in which we participate (life-deep). It is proposed that these practices are also the most powerful mediators in learning and that most of the learning that occurs across an individual's lifetime appears to occur outside schools, in various informal and non-formal environments (Banks et al., 2007). If we wish to deeply affect our students' learning, learning environments, including authentic and technology-enhanced activities, should be seen as part of an extended school environment (Edelson \& Reiser, 2006).

Complex challenges such as sustainable development (SD) as global phenomena are multifaceted in nature and require individuals with different points of view to collaboratively design and redesign solutions from various perspectives. According to Schank (2011), one major problem in current school systems is that teachers teach subjects instead of teaching students to think and act. If students are to participate in a society in which the construction, sharing and use of new knowledge and cultural artefacts are the basis for sustained development, their education should go beyond the learning of established knowledge (Kozma, 2011). We must also take into account that professions and personal lives have changed as compared to life in the industrial society and schools can no longer educate students about everything there is to know in a lifetime. Most students will tend to follow a working trajectory encompassing multiple careers, and students should be prepared for jobs that do not exist at the time of their schooling. Therefore, we need to enhance adaptive learning skills with the ability to learn and work in cross-disciplinary teams (National Education Technology Plan [NETP], 2010; Thomas \& Brown, 2011). Many researchers underline the so-called 'twenty-first century 
skills' such as communicating and collaborating to solve complex problems, adapting and innovating in response to new demands and changing circumstances and using technology to create new knowledge and expand human capacity and productivity (Binkley, Erstad, Herman, Raizen, Ripley, \& Rumble, 2011).

Sustained knowledge development is essential for social progress of all kinds, and the fundamental task of education is to enculturate youth into this knowledge-creating civilisation and to help them find a place in it (Scardamalia \& Bereiter, 2006). From a social perspective, there is a well-grounded need to move from individual learning and solo teaching to work in cross-disciplinary teams that encompass multiple ways of knowing (NETP, 2010). Classroom educators should build learning communities consisting of students, fellow educators and professional experts from museums, community centres and other settings, who can support a student's learning on demand (NETP, 2010) and enhance the activities in which students learn and work together with different roles, perspectives and responsibilities and apply their own expertise. This process would require confidence that the students can create knowledge that can be shared with their community for further knowledge building that is a legitimate part of civilisation (Scardamalia \& Bereiter, 2006).

Fischer and Redmiles (2008) proposed that, if the world outside school relies on collaboration, creativity and problem solving and requires dealing with uncertainty, change and intelligence distributed across cultures, disciplines and tools, then education should foster transdisciplinary activities that prepare students for having meaningful and productive lives in such a world. Having students become active agents in their lives and learning in settings far beyond classrooms, we must change our perception of what and how we teach in schools (NETP, 2010). If an innovation- and knowledgebased society is anticipated in the future, it calls for developing and implementing such pedagogy in teaching and learning for learners of all ages.

\section{Design-oriented pedagogy}

Building on the above-mentioned perspectives of learning, design-oriented pedagogy (Vartiainen, Liljeström, \& Enkenberg, 2012) was developed to enhance collaborative learning activities situated both in and out of school. The pedagogy is based on collaborative designing (Seitamaa-Hakkarainen, Viilo, \& Hakkarainen, 2010), highlighting the role of real-world phenomena and mediating objects and artefacts as a basis of the design and inquiry process. The pedagogy encourages approaching global phenomena such as SD from the perspective of learners' own ideas and interpretations, scaffolded by open-ended learning tasks that give students the opportunities to design and choose different kinds of perspectives and paths to engage inquiry (Liljeström, Enkenberg, \& Pöllänen, 2013).

The learning community consists of a student, fellow students and teachers, working with domain experts and other adults. New technology, especially social media and mobile technologies, provide great tools for collaboration, data collection and help to transform ideas into digital representations that can be jointly negotiated, developed and shared with a wider community. The structure of the design-oriented learning environment is like dynamic activity systems, where a community of learners negotiates common goals, divides duties and focuses their object-oriented and tool-mediated activities to accomplish the multifaceted learning task (cf. Engeström, 1987). The learning process is outlined in Figure 1 below (described in greater detail in Vartiainen et al., 2012). 


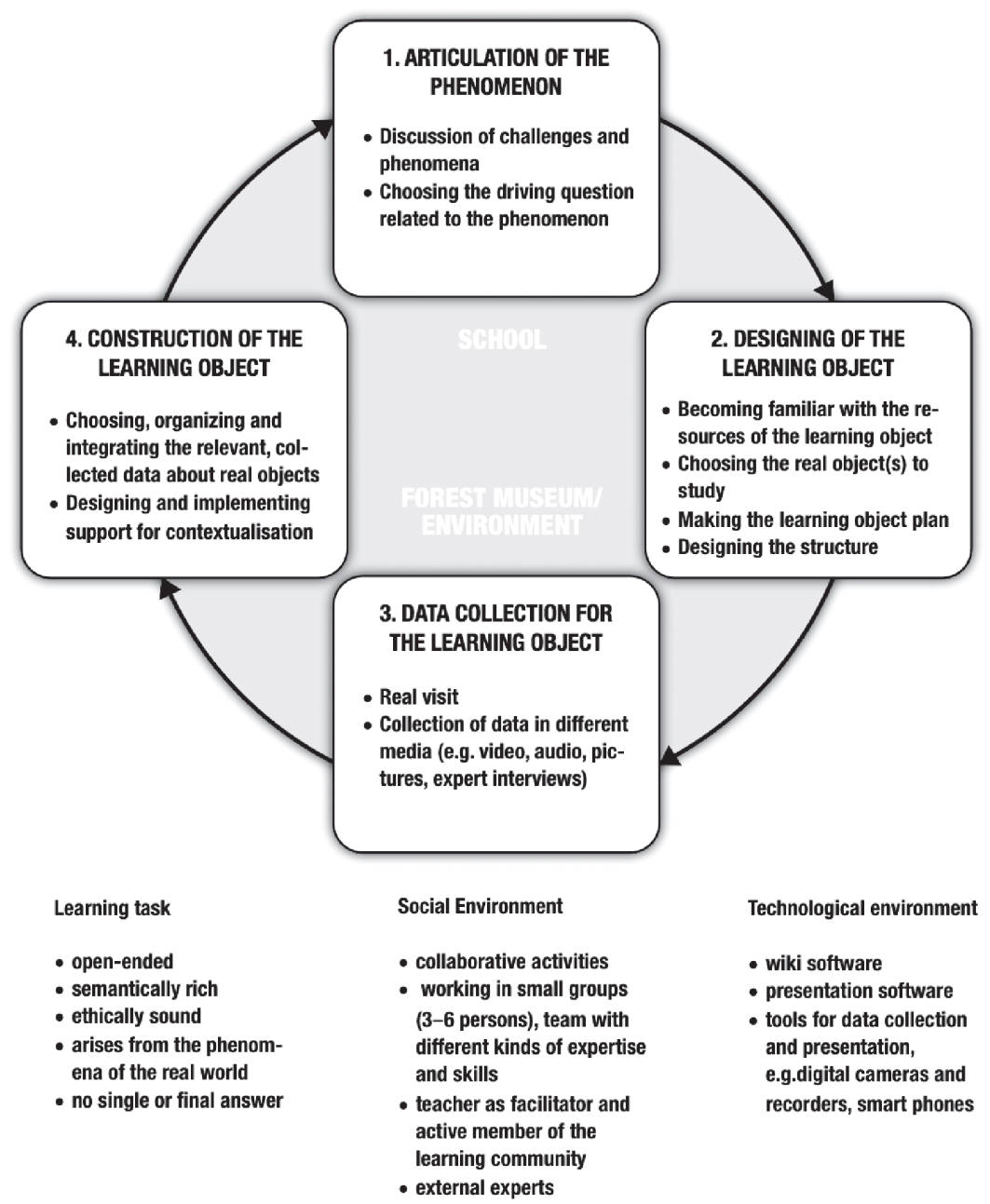

Figure 1. Instructional model for design-oriented pedagogy

\section{Research methods}

New educational innovations call for systematic research supporting development and implementation processes in a variety of contexts (Plomp, 2010). Therefore, many studies utilise the 'design-based research' approach to promote learning, create usable knowledge and advance theories of learning and teaching in complex settings (Design-based Research Collective, 2003). Following the principles of design-based research, the model of designoriented pedagogy has been tested and validated in several design experiments (iterative case studies) (Vartiainen et al., 2012; Liljeström et al., 2013). After several stages of development and prototyping research of the design-oriented pedagogy model, the main interest of the present study was to achieve a fuller implementation of the pedagogical model and to determine how teachers that represent different educational cultures and backgrounds experience this pedagogy (practicality) and their willingness to apply it in their teaching (relevance and sustainability) (Plomp, 2010). Based on these findings, the 
study then aimed to find answers to the following questions: What could be the problems, possibilities and possible users of the design-oriented pedagogy according to the participating teachers? and How did the teachers of the project envision the possibilities of the design-oriented pedagogy?

\section{Research object}

Some of the Case Forest project participants had previously formed a network, aiming to increase the education about SD and to improve the communication between foresters and the public. They found that a research group at the University of Eastern Finland had developed a new kind of instructional model that they thought would suit their goals and ought to be spread to other countries. Since the project focused on designoriented pedagogy and involved teaching and learning of the forest's role in a sustainable society, the pedagogy was termed "Case Forest Pedagogy". The role of the researchers was to introduce the model and its theoretical background and analyse the data produced by the participants.

The instructional model and its background were initially presented to the project participants in Estonia in January 2009. In the spring of 2009, the project participants and two teachers from each country attended a workshop in Finland. In this model course, the participants implemented their own learning projects related to the common theme of SD by designing learning objects from samples selected from the collections of the Finnish Forest Museum. Then, a similar course was arranged in every country. The project members and teachers attending the model course were responsible for implementing this teacher course in each country, with ten teachers per course. More than $80 \%$ of the participants in these teacher courses were women. Most of them had been teaching for more than ten years and had taught in a secondary school. Table 1 describes the responsible organisations and the total number of project participants from each of the participating countries.

Table 1. Responsible organisations and total number of participants in involved countries

\begin{tabular}{|c|c|c|c|}
\hline Country & $\begin{array}{l}\text { Number of } \\
\text { participants } \\
\text { (N) }\end{array}$ & $\begin{array}{c}\text { The responsible } \\
\text { organisations and number } \\
\text { of project participants }\end{array}$ & $\begin{array}{l}\text { Participants in teacher courses } \\
\text { organised by the project participants }\end{array}$ \\
\hline 1 & 2 & 3 & 4 \\
\hline Sweden & 16 & $\begin{array}{l}\text { Swedish Forest Agency } \\
(\mathrm{n}=4) \\
\text { Umea University }(\mathrm{n}=2)\end{array}$ & $\begin{array}{l}\text { Teachers in primary school } \\
(\mathrm{n}=10)\end{array}$ \\
\hline Finland & 14 & $\begin{array}{l}\text { Finnish Forest } \\
\text { Association }(\mathrm{n}=2) \\
\text { University of Eastern } \\
\text { Finland }(\mathrm{n}=2)\end{array}$ & $\begin{array}{l}\text { Teachers in pre-school }(\mathrm{n}=1) \\
\text { Teachers in primary school }(\mathrm{n}=3) \\
\text { Teachers in secondary school } \\
(\mathrm{n}=1) \\
\text { Other: teachers in a Steiner school, } \\
\text { professors of education, pre-service } \\
\text { teachers }(\mathrm{n}=8)\end{array}$ \\
\hline
\end{tabular}


Sequel to Table 1.

\begin{tabular}{|c|c|c|c|}
\hline 1 & 2 & 3 & 4 \\
\hline Estonia & 23 & $\begin{array}{l}\text { Estonian Forest } \\
\text { Industries Association } \\
(\mathrm{n}=3) \\
\text { State Forest Management } \\
\text { Centre }(\mathrm{n}=2) \\
\text { Estonian Biology and } \\
\text { Geography Teachers } \\
\text { Association }(\mathrm{n}=1)\end{array}$ & $\begin{array}{l}\text { Teachers in primary school }(\mathrm{n}=2) \\
\text { Teachers in secondary school } \\
(\mathrm{n}=13) \\
\text { Other: teachers in a nature school, } \\
\text { university student, communication } \\
\text { expert }(\mathrm{n}=2)\end{array}$ \\
\hline Latvia & 110 & Stora Enso $(\mathrm{n}=1)$ & $\begin{array}{l}\text { Teachers in primary, secondary } \\
\text { and upper secondary school } \\
(\mathrm{n}=109) *\end{array}$ \\
\hline Lithuania & 18 & $\begin{array}{l}\text { Kaunas College of } \\
\text { Forestry and Environ- } \\
\text { mental Engineering } \\
(\mathrm{n}=2)\end{array}$ & $\begin{array}{l}\text { Teachers in primary school }(\mathrm{n}=2) \\
\text { Teachers in secondary school } \\
(\mathrm{n}=12) \\
\text { Other: teachers in upper secondary } \\
\text { school, teachers in an agricultural } \\
\text { school }(\mathrm{n}=2)\end{array}$ \\
\hline Bulgaria & 15 & $\begin{array}{l}\text { University of Forestry } \\
(\mathrm{n}=3)\end{array}$ & $\begin{array}{l}\text { Teachers in secondary school } \\
(\mathrm{n}=12)\end{array}$ \\
\hline Slovakia & 16 & $\begin{array}{l}\text { National Forest Centre } \\
(\mathrm{n}=1)\end{array}$ & $\begin{array}{l}\text { Teachers in primary school }(\mathrm{n}=9) \\
\text { Teachers in secondary school } \\
(\mathrm{n}=4) \\
\text { Other: representatives from a } \\
\text { methodical-pedagogical centre for } \\
\text { teachers }(\mathrm{n}=2)\end{array}$ \\
\hline $\begin{array}{l}\text { The Czech } \\
\text { Republic }\end{array}$ & 9 & $\begin{array}{l}\text { Forest Management } \\
\text { Institute }(\mathrm{n}=1)\end{array}$ & $\begin{array}{l}\text { Teachers in secondary school } \\
(\mathrm{n}=5) \\
\text { Other: university lecturers, teachers } \\
\text { in a special education school, } \\
\text { Forest Pedagogy }(\mathrm{n}=3)\end{array}$ \\
\hline
\end{tabular}

* Details of the teachers' prior work experience were not included in the report from Latvia

The final meeting was held in Bulgaria in the summer of 2010.

\section{Data collection and analysis}

\section{Country reports and presentations}

To evaluate the teacher course, the project leaders from the Swedish Forest Agency designed a compulsory questionnaire that sought to identify teachers' backgrounds and their attitudes towards the model. The project members in each country translated the questionnaire into their native language and then summarised the results in English. In these country reports, the project members were asked to describe the teacher course that they organised, summarise the result of the course evaluation and answer the fol- 
lowing questions (designed by the project leaders) related to the pedagogy: 1) problems, 2) possibilities, 3) users, 4) dissemination of results and 5) EU policies and education systems. These country reports $(n=8)$ were used as the main source to answer the first research question. This paper focuses on the first four questions (because very few short answers were obtained in response to the question related to EU policies and education systems).

In the final meeting, the project members from each country also gave an approximately thirty-minute PowerPoint presentation on the basis of their written reports and experiences. All the presentations were recorded, transcribed and used as supplementary material in the data analysis.

\section{E-Questionnaire}

Before the meeting in Bulgaria, the project members were asked to participate in a short online questionnaire conducted by the researchers. The questionnaire focused on views about and experiences of the Case Forest Pedagogy. Thirteen people answered the questionnaire: project members from Lithuania $(n=4)$, Bulgaria $(n=1)$, the Czech Republic $(n=1)$, Sweden $(n=1)$, Latvia $(n=1)$, Estonia $(n=1)$ and Finland $(n=4)$. The questionnaire was used as supplementary material in the data analysis.

\section{Collaborative discussions}

The collaborative discussions held in Bulgaria after the presentations of each country were used as the main source to answer the second research question. The project participants were asked to divide themselves into two groups and discuss the following questions: What solutions can be provided by Case Forest Pedagogy to address the challenges we face in teaching and learning?

The discussions lasted for about 40 minutes. The discussions of both groups were recorded and transcribed with comprehensive coding. The first group had one member from Bulgaria, two from Finland, one from Latvia, two from Lithuania and one from Sweden. The second group had one member from Bulgaria, two from Estonia, one from Slovakia, one from the Czech Republic, two from Sweden.

\section{Data analysis}

We employed both theory- and data-driven qualitative content analysis (Mayring, 2000). For the first research question, the teachers' responses were coded after deductive, theorydependent content analysis. Categorisation was based on the questions used in the country reports. For the second research question, the teachers' responses were coded following inductive data analysis. The analysis involved three iterative phases (cf. Zhang, Hong, Scardamalia, Teo, \& Morley, 2011): a) identifying initial categories based on the teachers' responses; b) identifying similarities and differences among the initial categories and creating sub-categories; c) aggregating the categories into abstract interpretations about problems and possibilities of the pedagogy, elaborated more detailed in the following. 


\section{Results}

\section{Problems in implementing the pedagogy}

All countries except Finland, Bulgaria and the Czech Republic cited the lack of technological tools in schools. According to project participants from Slovakia, another problem encountered is that the students are more skilled in ICT than the teachers. The reports of Slovakia and Latvia mentioned the problem of the insufficient information technology (IT) skills of teachers and the recognition of this issue:

It is hard to neglect the fact that majority of teachers knew nothing about the possibilities afforded by IT. They are afraid to lose reputation. (country report; Latvia)

The participants also emphasised the activities and attitudes of the teachers. According to project participants from Estonia, Slovakia, Sweden, Finland and Lithuania, the teachers' attitudes present a problem, especially their attitudes towards new pedagogical approaches and new technology:

Older teachers are conservative and feel fear to use new methods. (presentation; Slovakia)

Also, the routine and lack of cooperation among teachers were mentioned in the report from Latvia. According to project participants from Finland, problems also exist in the general attitudes of students, colleagues and principals.

Also, problems related to organisational and administrative activities, such as the lack of time and financial resources, were mentioned. The Czech Republic and Latvia further stressed on the political regulation of education:

School reform (reduction of the number of teachers; increasing amount of work; increasing demand for paper work; reduction of salary) - very hard to be optimistic and creative in such kind of conditions. (country report; Latvia)

Forest pedagogy isn't certified by the Ministry of Education as an educational topic, and schools don't want to spend their money on uncertified courses; the Ministry of Agriculture doesn't have enough money to provide such courses for free. (presentation; Czech Republic)

The time constraints, structure of the school system and curriculum were broached by many project participants. However, the problem does not always exist in the curriculum itself, but rather in its implementation:

We don't have any constraints regarding the curriculum in Sweden. Outdoor teaching is a natural part of the school day in many schools, but many schools do not offer any outdoor education at all to their students. (questionnaire; Sweden)

Table 2 summarises the problems in implementing the design-oriented pedagogy. 
Table 2. Problems in implementing the pedagogy

\begin{tabular}{|c|c|c|c|c|c|c|c|c|}
\hline \multirow{2}{*}{ Problems of implementation } & \multicolumn{6}{|c|}{ COUNTRY } & \multirow{2}{*}{\multicolumn{2}{|c|}{$\mathrm{BG}^{*} * \mathrm{SE}$}} \\
\hline & $\mathrm{CZ}^{*}$ & EE & LV & SK & FI & LT & & \\
\hline \multicolumn{9}{|l|}{ Technological problems } \\
\hline Lack of equipment & & $\mathrm{X}$ & $\mathrm{X}$ & & & $\mathrm{X}$ & & $\mathrm{X}$ \\
\hline Teachers with insufficient IT skills & & & $\mathrm{X}$ & $\mathrm{X}$ & & & & \\
\hline \multicolumn{9}{|l|}{ Social attitude problems } \\
\hline $\begin{array}{l}\text { Attitudes of teachers towards new } \\
\text { technology }\end{array}$ & & $\mathrm{X}$ & $\mathrm{X}$ & & & & & \\
\hline $\begin{array}{l}\text { Attitudes of teachers towards new } \\
\text { pedagogical approaches }\end{array}$ & & $\mathrm{X}$ & $\mathrm{X}$ & $\mathrm{X}$ & & $\mathrm{X}$ & & $\mathrm{X}$ \\
\hline Attitudes of pupils, colleagues, or principal & & & & & $\mathrm{X}$ & $\mathrm{X}$ & & \\
\hline \multicolumn{9}{|l|}{ Contextual problems } \\
\hline Lack of financial resources & $\mathrm{X}$ & $\mathrm{X}$ & $\mathrm{X}$ & & & $\mathrm{X}$ & & \\
\hline Lack of time & & $\mathrm{X}$ & $\mathrm{X}$ & & $\mathrm{X}$ & $\mathrm{X}$ & & $\mathrm{X}$ \\
\hline Curriculum & & & & $\mathrm{X}$ & & $\mathrm{X}$ & & \\
\hline Political regulation of education & $\mathrm{X}$ & & $\mathrm{X}$ & & & & & \\
\hline
\end{tabular}

The Czech Republic, Estonia, Latvia, Slovakia, Finland, Lithuania, Bulgaria, Sweden

(*) Note that one teacher from the Czech Republic present at the Czech workshop discussed how to adapt the pedagogy to meet the mental level and technical abilities of the students. All the other teachers checked "no problems" to this question, but one teacher mentioned the lack of cameras and another mentioned the students' interest level as a problem.

(**) According to the report from Bulgaria, implementing this methodology would pose no problems. In the presentation, they mentioned "obligatory problems", but no further explanation was provided.

\section{Possibilities of the Case Forest Pedagogy}

The project participants from each country presented several possible future users for the method, from kindergarten to university and programmes outside of formal education, for instance, School educational programmes (the Czech Republic), RMK Nature Centres and Environmental Education Department of Environmental Board and Camp-schools (Estonia), kindergarten, primary school and secondary school teachers, youth education programmes (Finland), Professional Schools on Forestry and University of Forestry (Bulgaria) and high school schoolchildren, teachers themselves, primary schools, young forest friends cluster, seminars, extracurricular activities, camps, family gathering, distance studies (Lithuania).

The project participants from Estonia saw several possibilities for collaboration.

[The] Case Forest methodology develops cooperation between formal education system (schools) and informal education (museums/nature education centres), which strengthens networks for sustainable development.

The pedagogical model was also deemed appropriate for integrating different subjects in Estonia and Finland. In Sweden, the project members planned to continue collaboration with the teachers who attended their teacher course. 
Many project participants also discussed the learning possibilities created by the pedagogy:

It enables working outside the classroom, allows us to use inquiry as a learning method, makes learning methods more versatile, allows a child to be a subject of his [sic] learning, allows the cooperation of the pupils and changes the role of the teacher from a teacher to a co-learner. (questionnaire; Finland)

It is very good. Also, it is not a traditional way for education, and it will be very interesting for pupils and for teachers. (presentation; Bulgaria)

Also, in the reports of participants from Latvia and Slovakia, the Case Forest Pedagogy was seen as a way of changing the current models of education:

It also has a potential to be one of the important tools for realisation of reform in education system to change a traditional school to an advanced school by implementation of new methods and innovation involvement. (country report; Slovakia)

\section{Collaborative reflection of design-oriented pedagogy}

After reading the collaborative discussion transcripts several times, four discussion themes were identified in both the discussions (research question 2). Based on the teachers' responses, the initial categories were identified and divided into sub-categories (elaborated below) and ultimately into abstract interpretations about problems and possibilities of the pedagogy.

\section{Knowledge}

The nature of knowledge was the most common topic of discussion. For instance, a participant from Estonia in Discussion 1 said, "They (teachers) wanted to control this learning ... it (pedagogy) is very open ... They can't say that this knowledge and these skills. "Several comments were indicating that the pedagogy had challenged the teachers to see knowledge as developmental in nature. In Discussion 2, a participant from Sweden commented, "We don't give them (students) the answers either, they have to think for themselves." In Discussion 1, the participants saw the children taking on greater responsibility in knowledge development and started envisioning new possibilities in student learning by building bridges between the students and experts in terms of knowledge and practices. As an example, a participant from Finland said in Discussion 1, "Where could we find the answer and let's go ask some professional who could help us." In Discussion 1, another participant from Finland saw knowledge advancement as a community rather than individual achievement, "And questions might also be so complicated that you need ... several opinions ... and several people for them ... not one person can know all the answers ... you need the network."

Another example from the same Discussion 2 elaborates on the skills needed for living in the world where all the students do not have to have the same knowledge and competencies. 
Sweden 2: ... people who grow up now, they change jobs many times, and it is impossible for the school to prepare them for everything ... to know everything about everything... It's not possible ... but you can help them to ... know how to find ... how to learn ... the tools for managing ... in situations ... that is what the project is about.

Sweden 3 (continues): So Case Forest methodology is the part of life-long learning

\section{Learning task}

In Discussion 1, a participant form Finland strongly criticised the current practices.

The school system now and what kind of adults it brings out. They always want some manuals on how to behave, what to do. They are not making decisions by themselves because, if there is a curriculum, it says what you are supposed to learn. They are used to that system, and there is somebody who is saying what you are going to learn.

In the same discussion, a participant from Bulgaria brought up the challenge set by the extant curriculum.

Teacher should have some more freedom in curriculum, because the curriculum is obligatory ... [sic] ... because they have to implement their curriculum, and it is not possible to give different questions and different objects et cetera.

However, in Discussion 2, some comments about the open-learning task emphasised in the design-oriented pedagogy indicated a desire for clearer goals. A participant from the Czech Republic commented, "I think that there should be some kind of aim or target where to guide the students, there must be a sort of result." A participant from Slovakia responded similarly.

In Slovakia, teachers are used to set the object for doing something, so our teachers wanted us to help them formulate those objectives, set the goals to have clear objectives what pupils should know after this project.

In Discussion 1, a participant from Latvia commented that she experienced that reallife learning tasks can make learning more meaningful by giving the students the feeling of ownership of their own learning, "I know that pupils feel that it may be necessary to learn because it's real life, not this [sic] previous method of books and answers."

\section{Instructional model}

In Discussion 1, a participant from Lithuania described the current practices.

Our teachers have very conventional models, our students have trained how to answer, how to make some exercises and this Case Forest method is a new way, more creative.

In Discussion 2, one of the Estonian participants described the design-oriented pedagogy as collaborative inquiry, where students co-construct the process, "They 
have to discuss what problems they have to solve, and they have to do something to solve the problems."

The practices of today challenge the implementation of a new instructional model, as observed by a participant from Slovakia in Discussion 1.

It might be difficult to organise it in normal school life, because they have some lessons which are mattering [sic], and each teacher are [sic] responsible for different lessons, so they have to main an agreement to this topic, have enough space, enough time to use this methodology.

Despite such challenges, the participants suggested that the pedagogy can be seen as a cross-disciplinary inquiry that integrates multiple goals of curriculum and school subjects.

\section{Learning community}

In both groups, the role created by the pedagogy for the teachers provoked much discussion. The teacher still needs to interest students in the learning process and facilitate the inquiry process. However, the teacher does not have to control and know everything, as emphasised in Discussion 2 by a participant from Estonia, "The teachers are also learners, a teacher can learn from students [sic] and also these specialists from centres and museums that they do cooperation with."

Trust in student's agency and peer-to-peer teaching and learning also emerged in both discussions. In Discussion 2, a participant from Sweden stated, "They help each other and perhaps they have more fresh knowledge than teachers have, it is some kind of team work." A participant from Estonia described the emerged learning community and connected teaching, "The learning communities that we created during this methodology... [sic] ... They are team, there must be specialist and teachers and also students."

\section{Discussion and conclusion}

The results of the study indicate that in most of these countries, the participants perceived teachers' attitudes towards technology and new pedagogical approaches, lack of equipment, financial resources and time as problems to implementing this new approach. Many project members criticised the current subject-based school curriculum that offers limited opportunities to implement these deeply engaging and time-consuming learning methods. Overall, it seems that some of the Eastern European countries experienced problems related to political regulations of education and the financial constraints of learning institutes. In the Nordic countries, the problems were related to the teachers' attitudes and the strict division between school subjects and lessons.

Data analyses of collaborative discussion revealed four interconnected themes, providing an insight into the tension of current school practices and principles of the design-oriented pedagogy. Figure 2 describes the vast variation of teachers' reflections to knowledge, learning tasks, instructional models and social settings in learning. 
CURRENT PRACTICES

TEACHER

STUDENTS

COMMUNITY

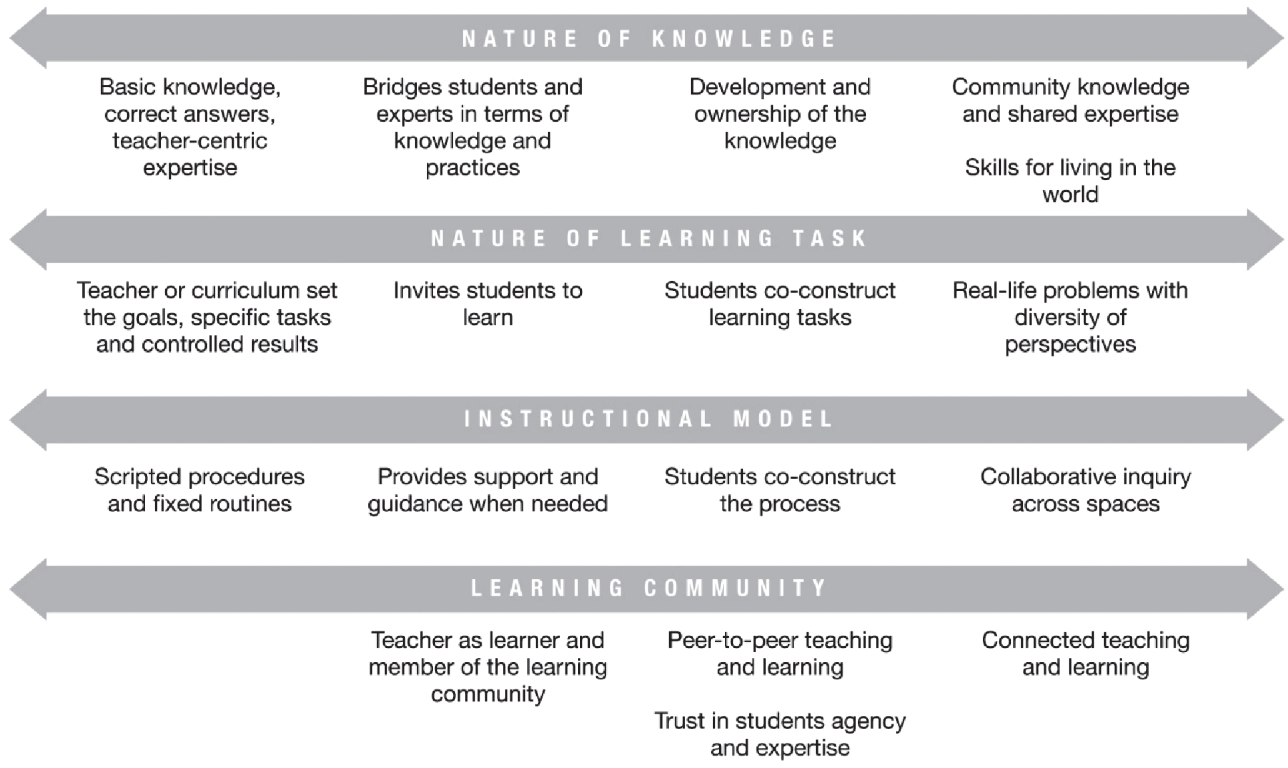

Figure 2. Challenges and possibilities of the design-oriented pedagogy

To summarise, the traditional forms of instruction, in which students study something constructed or announced by someone else, still seem to value factual knowledge and correct answers, where the teacher tries to guide the students with specific tasks, scripted procedures and fixed routines. Schools and teachers are used to thinking about what is needed to be learned in terms of school subjects (Schank, 2011), and teachers do not necessarily invent and implement new ways of using technology in their work (Valtonen, Pöntinen, Kukkonen, Dillon, Väisänen, \& Hacklin, 2011). Yet the complex challenges of society, such as SD, seem to generate pressing demands for teachers to transform their teaching methods. Beyond transmission of prevailing knowledge, design-oriented pedagogy was considered to be a co-developmental process that occurs in groups, communities and networks. A further step is to organise the students to work as a learning community pursuing to develop community knowledge by solving real-life problems with a diversity of perspectives. Breaking boundaries between school and cultural communities opens possibilities for connected teaching and facilitates the students' learning in settings beyond the classroom. However, this poses greater demands on teachers; they have to re-think the core issues of learning and teaching, create new meanings for themselves and understand the cultural contexts, practical conditions and barriers in different classroom settings to accordingly develop effective strategies (Zhang, 2010).

Design-oriented pedagogy is characteristic of what Zhang et al. (2011) referred to as a principle-based approach that defines core values and principles, leaving to teachers the challenge of reflective interpretation when applying these principles in different educational contexts. The four perspectives emphasised in collaborative discussions indicate that the current school practices and the new pedagogical approach affect one another in many ways, so that the actual pedagogical practices implemented in schools 
may share characteristics of both rather than correspond with the defined core values and principles. This reflects Zhang's (2010) argument that implementing new innovations provided by researchers is difficult, as the new practices are often assimilated into ongoing practice and are ritualised as surface procedures in implementation, without resulting in significant change.

The results of the study suggest that the participating teachers, coming from different educational backgrounds, perceived the pedagogy as an effective approach to facilitating a sustainable future. However, the differences in learning cultures and available resources are creating various challenges for the teachers to implement and sustain a designoriented pedagogy. To some extent, the result of the study reflects the beliefs, traditions and norms that organise the educational practices in these countries. One of the limitations in this study is that it cannot thoroughly explain the possible cultural differences in implementation of design-oriented pedagogy.

The most obvious limitation of the present study was the language barrier. The project members served as brokers (Wenger, 1998) between the teaching communities and researchers that created important opportunities to cross over the language differences and disseminate the pedagogical model, but also created a transparency issue. Also, the online questionnaire was in English, which could explain the very low response rate. According to Penuel, Fishman, Cheng and Sabelli (2011), because design-based researchers often seek to collaborate with teachers that are also 'ready for change', that may be a necessary condition for partnerships, but leaves open the question as to the scalability of the innovation.

After the final seminar, we have had the opportunity to observe the work of some Finnish project members (see Finnish Forest Association) and teachers (at the University of Helsinki, University Teacher Training School), who have organised workshops for other teachers and several learning projects with their students since their introduction to the program four years ago. These cases provide valuable avenues for future research for sustained innovation and understanding of the new ideas, designs and practices derived from the design-oriented pedagogy.

\section{Acknowledgements}

This study has been supported by the doctoral program for Multidisciplinary Research on Learning Environments (OPMON) and partly by the project "Blended learning: Technology-enhanced teaching and learning environments" (UEF, project No. S11822). We would like to thank professor Patrick Dillon and Anu Liljeström for fruitful discussions and comments on the manuscript.

\section{References:}

Banks, J., Au, K., Ball, P., Gordon, E., Gutierrez, K., Heath, S., ... Zhou, M. (2007). Learning in and out of school in diverse environments. Life-long, life-wide, lifedeep. Seattle, WA: The LIFE Center, University of Washington, Stanford University and SRI International.

Binkley, M., Erstad, O., Herman, J., Raizen, S., Ripley, M., \& Rumble, M. (2011). Defining 21st century skills. In P. Griffin, B. McGaw \& E. Care (Eds.), Assessment and teaching of 21st century skills (pp. 17-66). New York: Springer. 
Design-based Research Collective. (2003). Design-based research: An emerging paradigm for educational inquiry. Educational Researcher, 32(1), 5-8.

Edelson, D., \& Reiser, B. (2006). Making authentic practices accessible to learners. In K. Sawyer (Ed.), The Cambridge handbook of the learning sciences (pp. 335-354). Cambridge: Cambridge University Press.

Engeström, Y. (1987). Learning by expanding: An activity-theoretical approach to developmental research. Helsinki: Orienta-Konsultit.

Fischer, G., \& Redmiles, D. (2008). Transdisciplinary education and collaboration, contribution to the Human Computer Interaction Consortium (HCIC) Workshop 2008. Retrieved January 22, 2011, from http://13d.cs.colorado.edu/ gerhard/papers/ hcic2008.pdf

Kozma, R. (2011). A framework for ICT policies to transform education. In Transforming education: The power of ICT policies (pp. 19-36). Paris: UNESCO.

Law, N., Pelgrum, W., \& Plomp, T. (2008). Pedagogy and ICT use in schools around the world: Findings from the IEA SITES 2006 study. Hong Kong: Springer.

Liljeström, A., Enkenberg, J., \& Pöllänen, S. (2013). Making learning whole: An instructional approach for mediating the practices of authentic science inquiries. Cultural Studies of Science Education, 8(1), 51-86.

Mayring, P. (2000). Qualitative content analysis. Forum: Qualitative Social Research, 1(2), 120-130.

National Education Technology Plan. (2010). Transforming American education: Learning powered by technology. Retrieved October 2, 2010, from www.ed.gov/ technology/netp-2010

Penuel, W. R., Fishman, B. J., Cheng, B., \& Sabelli, N. (2011). Organizing research and development at the intersection of learning, implementation, and design. Educational Researcher, 40(7), 331-337.

Plomp, T. (2010). Educational design research: An introduction. In T. Plomp \& N. Nieveen (Eds.), An introduction to educational design research (pp. 9-35). Enschede, the Netherlands: SLO Netherlands Institute for Curriculum Development.

Scardamalia, M., \& Bereiter, C. (2006). Knowledge building: Theory, pedagogy, and technology. In K. Sawyer (Ed.), Cambridge handbook of the learning sciences (pp. 97-118). New York: Cambridge University Press.

Schank, R. (2011). Teaching minds. How cognitive science can save our schools. New York: Teachers College Press.

Seitamaa-Hakkarainen, P., Viilo, M., \& Hakkarainen, K. (2010). Learning by collaborative design: Technology-enhanced knowledge practices. International Journal of Technology and Design Education, 20(2), 109-136.

Thomas, D., \& Brown, J. S. (2011). A new culture of learning: Cultivating the imagination for a world of constant change. Lexington, KY: CreateSpace.

UNESCO (United Nations Educational, Scientific and Cultural Organisation). (1998). World education report 1998. Teachers and teaching in a changing world. Retrieved October 2, 2011, from http://www.unesco.org/pv_obj_cache/pv_obj_id_817A80F2 AF818D6C572E4FA8BF7323DC160C1E00/filename/wholewer98.PDF

UNESCO (United Nations Educational, Scientific and Cultural Organisation). (2005). Guidelines and recommendations for reorienting teacher education to address sustainability. Paris: UNESCO Education Sector. 
UNESCO (United Nations Educational, Scientific and Cultural Organisation). (2009). Review of contexts and structures for education for sustainable development: Learning for a sustainable world. Retrieved October 2, 2011, from http://unesdoc.unesco.org/ images/0018/001877/187757e.pdf

Valtonen, T., Pöntinen, S., Kukkonen, J., Dillon, P., Väisänen, P., \& Hacklin, S. (2011). Confronting the technological pedagogical knowledge of Finnish net generation student teachers. Technology, Pedagogy and Education, 20(1), 3-18.

Vartiainen, H., Liljeström, A., \& Enkenberg, J. (2012). Design-oriented pedagogy for technology-enhanced learning to cross over the borders between formal and informal environments. Journal of Universal Computer Science, 18(15), 2097-2119.

Wenger, E. (1998). Communities of practice: Learning, meaning, and identity. Cambridge: Cambridge University Press.

Zhang, J. (2010). Technology supported learning innovation in cultural contexts. Educational Technology Research and Development, 58(2), 229-243.

Zhang, J., Hong, H. Y., Scardamalia, M., Teo, C., \& Morley, E. (2011). Sustaining knowledge building as a principle-based innovation at an elementary school. Journal of the Learning Sciences, 20(2), 262-307.

\section{Correspondence:}

Henriikka Vartiainen, M.Ed., Junior Researcher, Philosophical Faculty, School of Applied Educational Science and Teacher Education, Savonlinna Campus, University of Eastern Finland. Postal address: P.O. Box 86, 57101 Savonlinna, Finland. Email: henriikka.vartiainen@uef.fi 